\title{
Papers
}

\section{Timing of birth and risk of multiple sclerosis: population based study}

Cristen J Willer, David A Dyment, A Dessa Sadovnick, Peter M Rothwell, T Jock Murray, George C Ebers for the Canadian Collaborative Study Group

\begin{abstract}
Objectives To determine if risk of multiple sclerosis (MS) is associated with month of birth in countries in the northern hemisphere and if factors related to month of birth interact with genetic risk.

Design Population based study with population and family based controls and a retrospective cohort identified from death certificates. A post hoc pooled analysis was carried out for large northern datasets including Sweden and Denmark.

Setting 19 MS clinics in major cities across Canada (Canadian collaborative project on the genetic susceptibility to multiple sclerosis); incident cases of MS from a population based study in the Lothian and Border regions of Scotland; and death records from the UK Registrar General.

Populations 17874 Canadian patients and 11502 British patients with multiple sclerosis.

Main outcome measure Diagnosis of multiple sclerosis.

Results In Canada ( $\mathrm{n}=17$ 874) significantly fewer patients with MS were born in November compared with controls from the population census and unaffected siblings. These observations were confirmed in a dataset of British patients $(n=11502)$, in which there was also an increase in the number of births in May. A pooled analysis of datasets from Canada, Great Britain, Denmark, and Sweden $(n=42$ 045) showed that significantly fewer $(8.5 \%)$ people with MS were born in November and significantly more $(9.1 \%)$ were born in May. For recent incident data, the effect of month of birth was most evident in Scotland, where MS prevalence is the highest.

Conclusions Month of birth and risk of MS are associated, more so in familial cases, implying interactions between genes and environment that are related to climate. Such interactions may act during gestation or shortly after birth in individuals born in the northern countries studied.
\end{abstract}

\section{Introduction}

Classic studies of twins, adoptees, half siblings, and families ${ }^{1-4}$ have led to a widely accepted notion that multiple sclerosis (MS) is a complex trait in which susceptibility is determined by the interplay of genes and environmental factors. Environment seems to influence risk at a population level, but specific details remain unclear. The most striking clue to the role of environment has always been the gradient with latitude, which is most obvious in Australia, where the risk in temperate Tasmania is fivefold that in subtropical Queensland ${ }^{56}$ but where ethnic origins are relatively uniform. The gradient is also seen in several other countries, including New Zealand ${ }^{7}$ and the United States. ${ }^{8}$
The role of environment is seen in twin studies, which report a $70-90 \%$ discordance in identical twins. ${ }^{1}$ Studies of migrants indicate that risk for MS is strongly associated with place of residence early in life, ${ }^{69}$ but it is not easy to retrospectively study gestational, perinatal, and childhood periods in adult onset diseases. In Canada, the risk for a dizygotic twin of someone with MS is almost twice that for a full non-twin sibling. ${ }^{1}$ This may implicate environmental factor(s) such as shared timing of gestation or birth, or both. Furthermore, the study of half siblings has shown a maternal effect that could be environmental in nature. ${ }^{5}$

Studies of month of birth and risk of MS have been carried out in several cohorts of people with MS, but sample sizes, ethnic groups, and statistical methods differed for each study and findings have been inconsistent. ${ }^{10-14}$ Although significant differences in month of birth compared with population based controls have been reported, they have not been for the same months.

\section{Methods}

Data on month of birth along with detailed information on demographics and clinical and family history were collected as part of the population based longitudinal Canadian collaborative project on genetic susceptibility to multiple sclerosis, ${ }^{15}$ in 17874 patients with MS. The first control group comprised all the recorded births in Canada from 1926 to 1970 (Statistics Canada). The months of birth in this group were used to calculate the expected numbers of births per month among patients with MS. A second control group comprised unaffected siblings of people with MS.

As Scandinavian studies have shown an increase of MS in people born in spring, we hypothesised a similar increase, but we analysed each month separately. We compared the births in a single month with the other 11 months for cases and controls (population or siblings) using a $2 \times 2 \chi^{2}$ test. For months for which we found no previous evidence of association, we corrected the $\mathrm{P}$ value for the 12 comparisons using Bonferroni correction.

For the matched affected-unaffected sibling group, we also applied McNemar's test. This test compares the number of pairs discordant for birth in a particular month by comparing the number of pairs where only the affected individual was born in that month and the unaffected individual was not $\left(\mathrm{N}_{\mathrm{a}}\right)$ with the number of pairs in which the unaffected individual was born in that month and the affected individual was not $\left(\mathrm{N}_{\mathrm{u}}\right)$. Under the null hypothesis of no association with disease, the statistic $\left(\mathrm{N}_{\mathrm{a}}-\mathrm{N}_{\mathrm{u}}\right)^{2} /\left(\mathrm{N}_{\mathrm{a}}+\mathrm{N}_{\mathrm{u}}\right)$ follows a $\chi^{2}$ distribution with $1 \mathrm{df}$.

We obtained datasets of patients from England, Wales $(n=8702)$, and Scotland $(n=2356)$ from death certificates that 
Table 1 Observed number of people in Canada with multiple sclerosis (MS) compared with expected number, according to month of birth

\begin{tabular}{|c|c|c|c|c|c|c|}
\hline \multirow[b]{2}{*}{ Month } & \multirow{2}{*}{$\begin{array}{c}\text { All births }(1926-70)(\mathrm{n}=13 \\
675451)\end{array}$} & \multicolumn{2}{|c|}{ People with MS ( $\mathrm{n=17}$ 874) } & \multirow[b]{2}{*}{ Observed/expected births (95\% CI) } & \multirow{2}{*}{$\begin{array}{l}\text { Month specific } \chi^{2} \text { test of } \\
\text { association }\end{array}$} & \multirow[b]{2}{*}{$P$ value } \\
\hline & & Observed No of births & Expected No of births & & & \\
\hline Jan & 1096651 & 1425 & 1433 & 0.99 (0.94 to 1.05$)$ & 0.05 & 0.82 \\
\hline Feb & 1032882 & 1369 & 1350 & 1.02 (0.96 to 1.07$)$ & 0.29 & 0.59 \\
\hline Mar & 1187630 & 1533 & 1552 & 0.99 (0.93 to 1.04$)$ & 0.26 & 0.61 \\
\hline Apr & 1168350 & 1532 & 1527 & 1.00 (0.95 to 1.06$)$ & 0.02 & 0.89 \\
\hline May & 1238935 & 1675 & 1619 & 1.04 (0.99 to 1.09$)$ & 2.10 & 0.15 \\
\hline Jun & 1202046 & 1512 & 1571 & 0.96 (0.91 to 1.01$)$ & 2.43 & 0.12 \\
\hline Jul & 1193942 & 1608 & 1561 & 1.03 (0.98 to 1.08$)$ & 1.58 & 0.21 \\
\hline Aug & 1156480 & 1553 & 1512 & 1.03 (0.98 to 1.08$)$ & 1.24 & 0.27 \\
\hline Sept & 1157627 & 1525 & 1513 & 1.01 (0.96 to 1.06$)$ & 0.10 & 0.75 \\
\hline Oct & 1114282 & 1455 & 1456 & 1.00 (0.95 to 1.05$)$ & 0.00 & 0.97 \\
\hline Nov & 1050758 & 1257 & 1373 & 0.91 (0.85 to 0.97) & 10.67 & 0.0011 \\
\hline $\mathrm{Dec}$ & 1075868 & 1430 & 1406 & 1.02 (0.96 to 1.07$)$ & 0.44 & 0.51 \\
\hline
\end{tabular}

${ }^{*} \mathrm{P}=0.013$ after Bonferroni correction for multiple comparisons.

mentioned "multiple sclerosis" and were registered in 1979-91. The controls for this sample were obtained from randomly selected death certificates of individuals born in the same year and country, with no mention of "multiple sclerosis." We also studied newly diagnosed cases from a population based study of the incidence of MS in the Lothian and Border regions of Scotland performed in 1992-5 inclusive $(\mathrm{n}=444)^{16}$ and used Scottish population birth records from 1940 to 1980 as controls (General Register Office Scotland).

\section{Results}

We compared the numbers of individuals with MS born in each month versus the other 11 months with population based controls. In the Canadian dataset $(\mathrm{n}=17874), 8.5 \%$ fewer people with MS were born in November; this was significant even after we corrected for the 12 monthly comparisons (1257 observed $v$ 1373 expected, $\chi^{2}=10.67, \quad \mathrm{P}=0.0011$ or $\mathrm{P}=0.013$ with Bonferroni correction) (table 1). The peak birth month for people with MS was offset six months, in May, though this was not significant $(\mathrm{P}=0.15)$. We found no difference within Canadian patients by sex, site of ascertainment, or decade of birth. Population control results, weighted to match patients with MS for year of birth, were similar to non-weighted controls (not shown). Among 67 Canadian patients with MS born in the southern hemisphere, eight were born in November and two in May, suggesting a reversal of the pattern in northern countries.

When we compared the dataset of British patients with MS, ascertained through death certificates and from incident cases $(n=11502)$, with controls obtained via similar methods we found significantly fewer people with MS had been born in November $\left(10.0 \%, \chi^{2}=6.80\right.$, uncorrected $\left.\mathrm{P}=0.009\right)$ and significantly more had been born in May $\left(16.3 \%, \chi^{2}=18.02\right.$, uncorrected $\mathrm{P}<0.0001$, corrected $\mathrm{P}=0.0003$ ) (table 2). The number born in December was also significantly lower $\left(\chi^{2}=4.8\right.$, $\mathrm{P}=0.028$ ), but this was not significant when we corrected for multiple comparisons. We combined the data for the 8702 cases from England and Wales according to death certificates, the 2356 cases from Scotland according to death certificates, and the 444 Scottish incident cases because each group had appropriately matched controls, all patients were from the same geographic region, and the confidence intervals of the odds ratios for May and November in each group substantially overlapped (odds ratio $1.30,95 \%$ confidence interval 1.17 to 1.44, for cases from England and Wales; 1.17, 0.94 to 1.47, for Scottish death certificate cases; and 1.89, 1.09 to 3.28, for Scottish incident cases).

We added Danish ${ }^{10}(n=6276)$ and Swedish ${ }^{11}(n=6393)$ samples to our Canadian $(\mathrm{n}=17874)$ and British samples $(\mathrm{n}=11502$; total $\mathrm{n}=42045)$. In this combined sample significantly more people with MS were born in May (9.1\%) and significantly fewer were born in November $(8.5 \%)$ (uncorrected and corrected $\mathrm{P}$ values for May and November were all $<0.0001)$ (fig 1, table 3). This represents a 19\% (odds ratio 1.19, 95\% confidence interval 1.14 to 1.25 ) decreased risk of MS for those born in November compared with those born in May.

In the Canadian dataset, we used a second control group of matched unaffected siblings. We had complete data on 9248 unaffected siblings from 7450 patients with MS. Index cases were matched with one non-twin sibling, which resulted in a dataset of

Table 2 Observed number of people in Great Britain with multiple sclerosis (MS) compared with expected number, according to month of birth

\begin{tabular}{|c|c|c|c|c|c|}
\hline \multirow[b]{2}{*}{ Month } & \multicolumn{2}{|c|}{ People with MS ( $n=11$ 502) } & \multirow[b]{2}{*}{ Observed/expected births (95\% Cl) } & \multirow{2}{*}{$\begin{array}{c}\text { Month specific } \chi^{2} \text { test of } \\
\text { association }\end{array}$} & \multirow[b]{2}{*}{$P$ value } \\
\hline & Observed No of births & Expected No of births & & & \\
\hline$\overline{J a n}$ & 1008 & 1000 & $1.01(0.93$ to 1.09$)$ & 0.04 & 0.83 \\
\hline$\overline{\text { Feb }}$ & 896 & 889 & 1.01 (0.93 to 1.09$)$ & 0.05 & 0.83 \\
\hline$\overline{\text { Mar }}$ & 975 & 986 & 0.99 (0.91 to 1.07$)$ & 0.09 & 0.77 \\
\hline$\overline{A p r}$ & 1004 & 973 & 1.04 (0.96 to 1.11$)$ & 0.73 & 0.39 \\
\hline May & 1137 & 978 & 1.18 (1.10 to 1.26$)$ & 18.02 & $<0.0001^{\star}$ \\
\hline Jun & 1013 & 967 & $1.05(0.97$ to 1.13$)$ & 1.57 & 0.21 \\
\hline Jul & 1013 & 980 & $1.04(0.96$ to 1.12$)$ & 0.80 & 0.37 \\
\hline Aug & 910 & 928 & $0.98(0.90$ to 1.06$)$ & 0.24 & 0.62 \\
\hline Sept & 915 & 936 & 0.98 (0.89 to 1.06$)$ & 0.33 & 0.56 \\
\hline Oct & 907 & 972 & $0.93(0.84$ to 1.01$)$ & 3.27 & 0.07 \\
\hline Nov & 823 & 914 & 0.89 (0.81 to 0.98$)$ & 6.80 & 0.009 \\
\hline$\overline{D e c}$ & 901 & 980 & 0.91 (0.83 to 0.99$)$ & 4.80 & 0.028 \\
\hline
\end{tabular}

${ }^{*} \mathrm{P}<0.0003$ after Bonferroni correction for multiple comparisons. 
Table 3 Observed number of people in northern hemisphere (Canada, Great Britain, Denmark, and Sweden) with multiple sclerosis (MS) compared with expected number, according to month of birth

\begin{tabular}{|c|c|c|c|c|c|}
\hline \multirow[b]{2}{*}{ Month } & \multicolumn{2}{|c|}{ People with MS ( $=44$ 045) } & \multirow[b]{2}{*}{ Observed/expected births ( $95 \% \mathrm{Cl}$ ) } & \multirow{2}{*}{$\begin{array}{c}\text { Month specific } \chi^{2} \text { test of } \\
\text { association }\end{array}$} & \multirow[b]{2}{*}{$P$ value } \\
\hline & Observed No of births & Expected No of births & & & \\
\hline$\overline{J a n}$ & 3428 & 3502 & 0.98 (0.95 to 1.01$)$ & 1.71 & 0.19 \\
\hline Feb & 3263 & 3252 & 1.00 (0.97 to 1.04$)$ & 0.04 & 0.84 \\
\hline Mar & 3753 & 3708 & 1.01 (0.98 to 1.05$)$ & 0.60 & 0.44 \\
\hline Apr & 3714 & 3629 & 1.03 (0.99 to 1.06$)$ & 2.20 & 0.14 \\
\hline May & 4056 & 3717 & 1.10 (1.07 to 1.13$)$ & 33.88 & $<0.0001^{*}$ \\
\hline Jun & 3608 & 3583 & 1.01 (0.97 to 1.04$)$ & 0.18 & 0.67 \\
\hline Jul & 3697 & 3592 & 1.03 (1.00 to 1.07$)$ & 3.37 & 0.07 \\
\hline Aug & 3492 & 3473 & 1.01 (0.97 to 1.04$)$ & 0.11 & 0.74 \\
\hline Sept & 3444 & 3499 & 0.98 (0.95 to 1.02) & 0.95 & 0.33 \\
\hline$\overline{\text { Oct }}$ & 3354 & 3439 & 0.97 (0.94 to 1.01) & 2.26 & 0.13 \\
\hline Nov & 2974 & 3252 & 0.91 (0.87 to 0.95$)$ & 25.74 & $<0.0001^{\star}$ \\
\hline$\overline{D e c}$ & 3262 & 3399 & 0.96 (0.92 to 0.99$)$ & 6.01 & $0.014 \dagger$ \\
\hline
\end{tabular}

*Also $\mathrm{P}<0.0001$ after Bonferroni correction for multiple comparisons.

$\dagger \mathrm{P}=0.17$ after Bonferroni correction for multiple comparisons.

4232 affected-unaffected sibling pairs. We observed a slight correlation in the month of birth for closely spaced siblings, but not among more distantly spaced offspring (data not shown). To account for this effect, when there was more than one unaffected sibling we selected the one furthest in age from the index case. This group showed no significant correlation for month of birth in sibling pairs $(\mathrm{P}=0.30)$. We compared affected siblings with their matched unaffected siblings using McNemar's test for November birth and observed 273 pairs in which the affected member of the pair was born in November and 343 where the unaffected sibling was born in November. The result was significant for difference in November births $(\mathrm{P}=0.0048)$. Selection of the unaffected sibling closest in age also yielded a significant difference $(\mathrm{P}=0.0018)$.

We tested whether the environmental component related to month of birth might contribute to familial risk, perhaps by interacting with susceptibility genes predictably enriched in families with multiple cases of MS. ${ }^{15}$ Among affected people with a family history of MS we found $16.2 \%$ fewer were born in November relative to population controls compared with $3.0 \%$ fewer among those with no family history of MS $\left(\chi^{2}=3.92\right.$, $\mathrm{P}=0.050$ ). We found no difference when we divided affected individuals into fourths according to age of onset (data not shown).

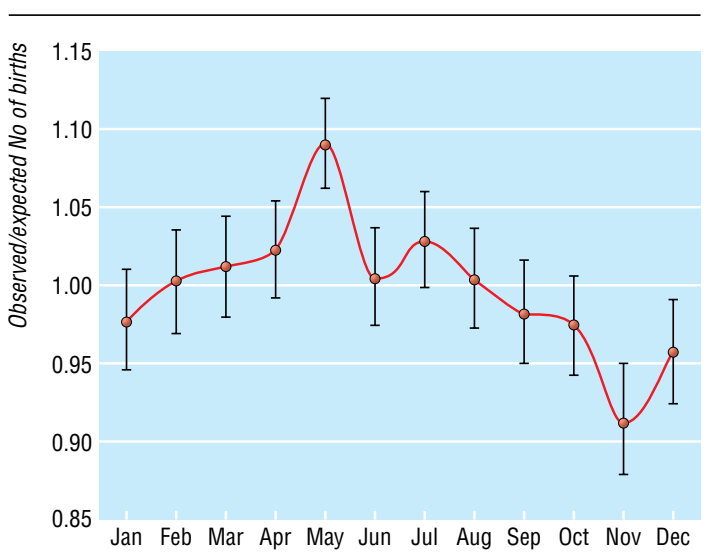

Month

Fig 1 Pooled analysis of observed/expected births in people with multiple sclerosis in Canadian, British, Danish, and Swedish studies ( $n=42$ 045) with $95 \%$ confidence intervals
We also compared the odds ratio for increased risk of MS for people born in May compared with November. We used incident cases only to allow consistency among the countries examined. The highest odds ratio for May/November risk was in Scotland (1.89, 1.09 to 3.28), followed by Denmark (1.22, 1.08 to 1.38), Sweden $(1.18,1.05$ to 1.33$)$, and Canada (1.13, 1.05 to 1.22$)$ (fig 2).

\section{Discussion}

Among Canadian patients with MS 8.5\% fewer than expected were born in November compared with other months and slightly but not significantly more were born in May. This finding was replicated in British patients with MS, where the numbers born in both months were significantly different from controls. A pooled analysis including results from previously published Danish $^{10}$ and Swedish ${ }^{11}$ studies confirmed the May peak and November nadir. This overall dataset of patients with MS born in the northern hemisphere showed a 13\% increase in risk of MS for those born in May compared with November (95\% confidence interval $5 \%$ to $22 \%$ ).

We used unaffected siblings from the Canadian collaborative project $^{15}$ as a second control group, eliminating potential confounding by ethnic differences in seasonal birth patterns or by survival being influenced by month of birth. The unaffected

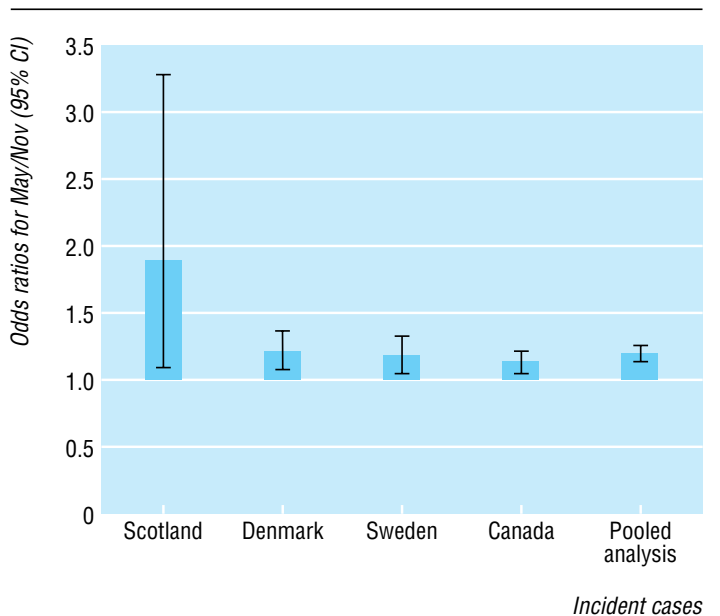

Fig 2 Odds ratios for people with multiple sclerosis being born in May/November among incident cases in northern hemisphere countries 
sibling controls confirmed and extended the findings as they also differed from population controls in a direction opposite to that of their affected siblings. This may be viewed as internal confirmation of the effect of month of birth on risk.

The results were derived from more than 42000 patients with MS from northern countries, where MS has a high prevalence. Canada, Denmark, ${ }^{10}$ Great Britain, and Sweden ${ }^{11}$ each have large databases and distinct seasons, and nearly all cases of MS in Canada are identified..$^{15}$

We have conclusively shown the association between month of birth and risk of MS in northern countries. The sample size, internal replications, and selection of appropriate controls indicate that this is unlikely to be an artefact. Our pooled data show that being born in May is associated with increased risk, and the Canadian and British datasets clearly show that people born in November have the lowest risk. Correlation of specific years of increased risk related to season with features such as ultraviolet radiation, temperature, or weather patterns may help to elucidate this effect further.

Month of birth and risk of MS has been examined in other populations. The Danish study found that more people with MS had been born in March, April, May, and June, and a Swedish study showed an association with March, May, and July. ${ }^{11}$ When these data were combined, more people with MS had been born in the five consecutive months from March to July, ${ }^{2}$ although the Swedish study did not directly confirm the Danish findings. Smaller studies in cohorts from Sicily, ${ }^{13}$ the Netherlands, Japan, and Hungary ${ }^{14}$ were not consistent, but a study from Vancouver showed the same degree of effect in a smaller sample size. ${ }^{12}$ Relatively small sample sizes may not have sufficient power to disentangle meaningful seasonal influences. ${ }^{14-17}$ None of these studies can be considered as definitive.

Although the birth month results in MS now seem clear, the interpretation is not. May and November show significance in the pooled analysis and the peaks of altered risk are exactly six months apart. Although the reduced risk for November seems to exist also for December births in some datasets, the changes in risk are remarkably discrete. The abrupt change in risk by month suggests a threshold effect for both increased and decreased risk, something that is not easily explained. These observed changes may partly explain the increased risk of MS in second generation Asian and Caribbean migrants to the United Kingdom-that is, moving to the United Kingdom does not changes their genes but something in the climate may do so. ${ }^{18}$

\section{Possible explanations of association}

The risk factor(s) responsible for the effect of timing of birth must vary seasonally and probably interacts with development of the central nervous system or immune systems, or both. Among candidate factors are maternal folate,$^{19}$ correlates of infant birth weight and virus infection, and factors also implicated in the effect of season of birth on schizophrenia. ${ }^{17}$ Undoubtedly other cyclic interactions remain to be identified.

Previous findings of associations between higher latitudes and risk of MS (Sardinians and Sami being notable exceptions) have suggested that exposure to the sun may account for the geographical variation of MS. ${ }^{20}$ Most biologically active vitamin $\mathrm{D}$ is generated in the skin with exposure to ultraviolet radiation ${ }^{21}$ and an increased risk of MS related to month of birth could reflect well documented seasonal deficiency in maternal concentrations of vitamin $\mathrm{D}^{22}$ Vitamin $\mathrm{D}$ treatment reduces severity of symptoms and progression in experimental autoimmune encephalomyelitis (EAE), which is a mouse model of MS. ${ }^{23}$ Furthermore, exposure to sun during childhood is associated
What is already known on this topic

Susceptibility to multiple sclerosis (MS) is influenced by genetic and environmental factors

An association with latitude in early life has been shown in migrants from regions of differing risk

A maternal parent of origin effect shown in half siblings with MS from Canada suggested that environment acts in gestation or the neonatal period to determine risk for this adult onset disease

\section{What this study adds}

In northern countries the risk of MS is greater for people born in May and lower for those born in November

This effect is greater in Scotland, where the population prevalence of this disease is highest

These findings support suggestions from studies in twins and half siblings that the gestational or neonatal environment, or both, influence the risk of MS later in life

with a reduced risk of multiple sclerosis, ${ }^{24}$ and this may also extend to timing of birth. If the excess of MS in those born in May is related to maternal vitamin D deficiency, studies on blood concentrations suggest that the end of the second or the third trimester are the crucial time points..$^{22}$ Vitamin D receptors are present in the brain, and gestational vitamin D deficiency has striking effects on brain development in experimental animals. ${ }^{25}$

The observed May/November birth ratio in living incident cases from Scotland (1.89), Denmark (1.22), ${ }^{10}$ Sweden (1.18), ${ }^{11}$ and Canada (1.13) decreases in order of population prevalence (fig 2). This suggests that the seasonal birth effect may be connected with environmental factors determining prevalence rates. These are powerful, seem to act at a broad population level,,${ }^{1-3}$ and may hold the key to disease prevention. The "parent of origin" effect, recently reported in MS, ${ }^{5}$ may suggest that, at least in part, environmental factors are maternally mediated and influence development in the nervous or immune system, or both.

We thank Irene Yee, Maria Criscuoli, Randy Holmes, Kevin Atkins, and Don Templer (at Alliant International University) for their help with this study and James Gowans, Rodney Phillips, Anne Spurkland, Pierre Duquette, Ed Burton, Stacey Cherny, Iain Chalmers, and Michael Boehnke for help with the manuscript. We also thank the participants of the vitamin D workshop held in Toronto in April 2002 for valuable insight, discussion, and advice and Nina Jablonski and George Chaplin for sharing their expertise.The Canadian Collaborative Study Group includes D W Paty, S A Hashimoto, V Devonshire, J Hooge, J Oger, L Kastrukoff, and T Traboulsee (Vancouver); L Metz (Calgary); S Warren (Edmonton); W Hader (Saskatoon); R Nelson and M Freedman (Ottawa); D Brunet (Kingston); J Paulseth (Hamilton); G Rice and M Kremenchutzky (London); P O'Connor, T Gray, and M Hohol (Toronto); P Duquette and Y Lapierre (Montreal); J-P Bouchard (Quebec City); V Bhan and C Maxner (Halifax); and W Pryse-Phillips and M Stefanelli (St Johns).

Contributors: GCE (guarantor) conceived the Canadian national network of MS clinics and its role in this study. ADS and GCE conceived this investigation and are the principal investigators of the Canadian collaborative study. GCE and ADS supervised the data collection and research. CJW and $\mathrm{DAD}$ did the primary analyses for the Canadian dataset, and PMR conceived the study and completed analyses of the UK dataset. CJW wrote the first draft, with subsequent revision from all authors. TJM provided a helpful suggestion for future research.

Funding: This work was part of a larger project funded by the MS Society of Canada Scientific Research Foundation. CJW and DAD were supported by 
studentships from the MS Society of Canada, during the time this study was mainly completed. ADS is a Michael Smith Distinguished Scholar.

Competing interests: None declared.

Ethical approval: The study was approved by the University of Western Ontario and the University of British Columbia, which were the two main sites of data collection. Each Canadian MS clinic obtained ethical approval from their local review board.

1 Willer CJ, Dyment DA, Risch NJ, Sadovnick AD, Ebers GC. Twin concordance and sibling recurrence rates in multiple sclerosis. Proc Natl Acad Sci U S A 2003;100:12877-82.

Ebers GC, Sadovnick AD, Risch NJ. A genetic basis for familial aggregation in multiple Ebers GC, Sadovnick AD, Risch NJ. A genetic basis for familial aggregation
sclerosis. Canadian Collaborative Study Group. Nature 1995;377:150-1.

3 Ebers G, Sadovnick A, Dyment D, Yee I, Willer C, Risch N, et al. A parent of origin effect in multiple sclerosis: observations in half siblings. Lancet 2004;363:847-50.

4 Ebers GC, Yee IM, Sadovnick AD, Duquette P. Conjugal multiple sclerosis: populationbased prevalence and recurrence risks in offspring. Canadian Collaborative Study Group. Ann Neurol 2000;48:927-31.

5 McLeod JG, Hammond SR, Hallpike JF. Epidemiology of multiple sclerosis in Australia. With NSW and SA survey results. Med J Aust 1994;160:117-22.

6 Hammond SR, English DR, McLeod JG. The age-range of risk of developing multiple sclerosis: evidence from a migrant population in Australia. Brain 2000;123:968-74

7 Fawcett J, Skegg DCG. Geographic distribution of MS in New Zealand: evidence from hospital admissions and deaths. Neurology 1988;38:416-8.

8 Templer DI, Trent NH, Spencer DA, Trent A, Corgiat MD, Mortensen PB, et al Season Templer DI, Trent NH, Spencer DA, Trent A, Corgiat MD, Mor
of birth in multiple sclerosis. Acta Neurol Scand 1992;85:107-9.

9 Wiberg M, Templer DI. Season of birth in multiple sclerosis in Sweden: replication of Denmark findings. J Orthomol Med 1994;9:71-74.

10 Kurtzke JF, Beebe GW, Norman JE Jr. Epidemiology of multiple sclerosis in US veterans: 1. race, sex, and geographic distribution. Neurology 1979;29:1228-35.

11 Dean G. Annual incidence, prevalence, and mortality of multiple sclerosis in white South-African-born and in white immigrants to South Africa. BMJ 1967;ii:724-30.

12 Sadovnick AD, Yee IM. Season of birth in multiple sclerosis. Acta Neurol Scand 1994:89:190-1.

13 Salemi G, Ragonese P, Aridon P, Reggio A, Nicoletti A, Buffa D, et al. Is season of birth associated with multiple sclerosis? Acta Neurol Scand 2000;101:381-3.

14 Torrey EF, Miller J, Rawlings R, Yolken RH. Seasonal birth patterns of neurological disorders. Neuroepidemiology 2000;19:177-85.

15 Sadovnick AD, Risch NJ, Ebers GC. Canadian collaborative project on genetic susceptibility to MS, phase 2: rationale and method. Canadian Collaborative Study Group. Can J Neurol Sci 1998;25:216-21.

16 Rothwell PM, Charlton D. High incidence and prevalence of multiple sclerosis in south east Scotland: evidence of a genetic predisposition. J Neurol Neurosurg Psychiatry $1998 ; 64: 730-5$.
17 Torrey EF, Miller J, Rawlings R, Yolken RH. Seasonality of births in schizophrenia and bipolar disorder: a review of the literature. Schizophr Res 1997;28:1-38.

18 Elian M, Dean G. Multiple sclerosis among the United Kingdom-born children of immigrants from the West Indies. J Neurol Neurosurg Psychiatry 1987;50:327-32.

19 Branda RF, Eaton JW. Skin color and nutrient photolysis: an evolutionary hypothesis Science 1978;201:625-6.

20 Acheson ED, Bachrach CA, Wright FM. Some comments on the relationship of the distribution of multiple sclerosis to latitude, solar radiation and other variables. Acta Psychiat (Scand) 1960;35(suppl 147):132.

21 Holick MF, Smith E, Pincus S. Skin as the site of vitamin D synthesis and target tissue for 1,25-dihydroxyvitamin D3. Use of calcitriol (1,25-dihydroxyvitamin D3) for treatment of psoriasis. Arch Dermatol 1987;123:1677-83a.

22 Vieth R, Cole DE, Hawker GA, Trang HM, Rubin LA. Wintertime vitamin D insufficiency is common in young Canadian women, and their vitamin D intake does not prevent it. Eur J Clin Nutr 2001:55:1901-7.

23 Cantorna MT, Hayes CE, DeLuca HF. 1,25-Dihydroxyvitamin D3 reversibly blocks the progression of relapsing encephalomyelitis, a model of multiple sclerosis. Proc Natl Acad Sci U S A 1996;93:7861-4.

24 Van der Mei IA, Ponsonby AL, Dwyer T, Blizzard L, Simmons R, Taylor BV, et al. Pas exposure to sun, skin phenotype, and risk of multiple sclerosis: case-control study. $B M J$ 2003;327:316.

25 McGrath JJ, Feron FP, Burne TH, Mackay-Sim A, Eyles DW. Vitamin D3-implications for brain development. J Steroid Biochem Mol Biol 2004;89-90:557-60.

(Accepted 3 November 2004)

doi $10.1136 /$ bmj.38301.686030.63

Department of Biostatistics, University of Michigan, Ann Arbor, MI 48109, USA Cristen J Willer postdoctoral fellow

Wellcome Trust Centre for Human Genetics, University of Oxford, Oxford OX3 7BN

David A Dyment doctoral student

Department of Medical Genetics and Faculty of Medicine (Division of Neurology), University of British Columbia, Vancouver, BC, Canada V6T 2B5

A Dessa Sadovnick professor

Department of Clinical Neurology, Radcliffe Infirmary, University of Oxford, OX2 $6 \mathrm{HE}$

Peter M Rothwell professor

George C Ebers action research professor

Dalhousie University, Halifax, NS, Canada B3H 4R2

$\mathrm{T}$ Jock Murray professor of medicine

Correspondence to: G C Ebers george.ebers@clneuro.ox.ac.uk 